\title{
Специфика формирования сенсорно-перцептивных процессов у старших школьников с интеллектуальной недостаточностью
}

\author{
Мария Б. Вихарева \\ Южный фелеральный университет, г. Ростов-на-Аону, Россия \\ E-mail: vixareva-mariya@mail.ru
}

\begin{abstract}
Аннотация
В $а$ анной статье полробно раскрывается формирование сенсорно-перцептивных процессов у Аетей старшего школьного возраста, имеющих интемлектуальную неАостаточность. После введения, в котором раскрывается актуальность, в статье отображено, что вкАючает в себя понятие «сенсорно-перцептивные процессы», какую характеристику этим процессам Аают в психологии. В слеАующем подразделе автором был провеАен анализ теоретических материалов, позволивший опреАелить ряд особенностей, которыми можно охарактеризовать специфику фрормирования сенсорно-перцептивной стороны познавательной сореры обучающихся старшей шкомы, которые имеют интемектуальные нарушения. Аия осуществления теоретического анализа были использованы данные исследований таких ученых, как С. Я. Рубинштейн, А. А. Виногралова, А. М. Мамлаев, О. А. Бажукова, П. О. Омарова и др.

Аалее в статье автором были объединены полученные в ходе проведения эксперимента результаты наблюАения за учениками специальной школы в процессе коррекционно-развивающей работы. Ввиду того, что методика по теме исслеАования преАполагала использование мнемотехник, в частности «Mind maps», созАанной американским ученым Т. Бьюзеном, нам удалось выявить значимые А^я нас особенности восприятия схематических изображений, создаваемых самостоятельно учащимися с ментальной неАостаточностью.

В работе нашла отражение и проблема Аистанционного обучения. Автором рассматривается изменение эфорективности коррекционных и развивающих занятий при перехоле в онлайн-фоормат. Констатируется корреляция межАу ощущениями разных моАальностей и способностями к восприятию. В заключение подчеркивается, что Аети старшего школьного возраста с интемлектуальной неАостаточностью имеют потенциальные возможности сенсорно-перцептивного развития.
\end{abstract}

\section{КАючевые слова}

сенсорно-перцептивные процессы, особенности ощущения, специорика восприятия, чувствительность, интемектуальная неАостаточность, школьники старших классов, Аисгармоничное сенсорно-перцептивное развитие, специфика фороиирования перцепции, Аистанционное обучение, мнемотехники 
КОРРЕКЦИОННАЯ ПСИХОЛОГИЯ

А^я цитирования: Вихарева М. Б. Специфика формирования сенсорно-перцептивных процессов у старших школьников с интеллектуальной неАостаточностью // Северо-Кавказский психологический вестник. 2020. №18/2. С. 5-14. doi: 10.21702/ncpb.2020.2.1

\title{
Specificity of the formation of sensory-perceptual processes in senior schoolchildren with intellectual disabilities
}

\author{
Mariya B. Vikhareva \\ Southern Federal University, Rostov-on-Don, Russia \\ E-mail: vixareva-mariya@mail.ru
}

\begin{abstract}
This article reveals in detail the formation of sensory-perceptual processes in children of senior school age with intellectual disabilities. After the introduction, which reveals the relevance, the article displays what the concept of "sensory-perceptual processes" includes, what characteristics to these processes are given in psychology. In the next subsection, the author analyzed theoretical materials, which made it possible to determine a number of features that can characterize the specificity of the formation of the sensory-perceptual side of the cognitive sphere of high school students who have intellectual disabilities. To carry out the theoretical analysis, research data from such scientists, as S. Ya. Rubinshtein, A. D. Vinogradova, D. M. Mallaev, O. A. Bazhukova and P. O. Omarova and others, were used.

Further in the article, the author combined the results of observation of the students of a special school in the course of correctional and developmental work obtained during the experiment. In view of the fact that the methodology of work on the research topic involved the use of mnemonics, in particular Mind maps, created by the American scientist T. Buzan, we were able to identify the peculiarities of the perception of schematic images created independently by students with mental disabilities that are significant for us. The work also reflects the problem of distance learning. The author examines the change in the effectiveness of correctional and developmental classes during the transition to the online format. The correlation between sensations of different modalities and perception abilities is stated. In the conclusion, it is emphasized that children of senior school age with intellectual disabilities have the potential for sensory-perceptual development.
\end{abstract}

\section{Keywords}

sensory-perceptual processes, peculiarities of sensation, specificity of perception, sensitivity, intellectual disabilities, high school students, disharmonious sensory-perceptual development, specificity of formation of perception, distance learning, mnemonics 
For citation: Vikhareva M. B. Specificity of the formation of sensory-perceptual processes in senior schoolchildren with intellectual disabilities. Severo-Kavkazskii psikhologicheskii vestnik = North-Caucasian Psychological Bulletin, 2020, no. 18/2, pp. 5-14. doi: 10.21702/ ncpb.2020.2.1 (in Russ.).

\section{ВВЕДЕНИЕ}

Знакомство с окружающим миром происходит в первые секунды рождения человека. При появлении на свет осуществляется переход от одного мира, уже привычного, к новому, еще неизведанному. Если мы хотим дать наиболее верную характеристику своеобразному психическому состоянию новорожденного ребенка, лучше всего будет обратиться к Л. С. Выготскому, который описывал его как исключительное преобладание недифференцированных, нерасчлененных переживаний, представляющих как бы сплав влечения, аффекта и ощущения, невыделенность себя и своих переживаний из восприятия объективных вещей, неразличение социальных и физических объектов [1].

Ребенок получает немыслимый объем информации разной модальности сразу после рождения. И именно с этого момента начинается познание мира. Что же такое познание? Познание - это процесс деятельности человека, направленный на получение и развитие новых знаний. Из каких менее глобальных процессов он состоит?

Ощущения и восприятие - это те аспекты, с которых начинается процесс познания. Ощущения являются отражением воспринимаемых рецепторами органов чувств отдельных свойств явлений и предметов в сознании человека. Они служат первоначальным источником всех знаний человека об окружающей его действительности. Мир, видимый и слышимый, состоящий из палитры самых разнообразных красок, форм, звуков, становится доступным детям по мере развития ощущений, которые основаны на рефлекторной деятельности мозга и имеют взаимосвязь и с речевой, и с иными видами деятельности. Они являются частным элементом, включенным в процесс восприятия [2].

Процесс восприятия позволяет целостно отражать предметы и явления окружающего при непосредственном воздействии внешних и внутренних раздражителей на органы чувств человека. Основой восприятия являются сложные условно-рефлекторные связи. Процесс восприятия неразрывно связан с ощущением, представлениями, мышлением и речью. Если нарушается развитие тех или иных сторон психики, это непосредственно негативным образом влияет и на процесс восприятия. Процессы восприятия и ощущения относятся к сенсорно-перцептивным [3]. 
КОРРЕКЦИОННАЯ ПСИХОЛОГИЯ

\section{Теоретическое обоснование}

В данной статье нами проведен теоретический обзор специфики сенсорно-перцептивного развития школьников с интеллектуальными нарушениями. Целью статьи является не только представление собранных сведений об уже изученных особенностях перцепции детей данной категории, но обобщение собственных наблюдений при работе с такими детьми. Высокая распространенность интеллектуальных нарушений и исследовательских работ, связанных с ними, обуславливает многообразие материала для обзора выбранной нами сферы. Из всех исследований более всего мы обращались к трудам С. Я. Рубинштейна [4], А. Д. Виноградовой [5], Д. М. Маллаева, О. А. Бажуковой и П. О. Омаровой [6].

Дисгармоничный путь формирования познавательной сферы, куда входит и сенсорно-перцептивная организация, у детей с недостаточностью интеллекта несет в себе обусловленность недоразвитием коры больших полушарий головного мозга диффузного характера. Нарушения могут возникать и на периферическом уровне, и на проводниковом уровне, и на уровне определенных зон коры головного мозга [7].

В работах Л. В. Занкова мы можем увидеть, что у школьников с ментальными нарушениями специфика сенсорно-перцептивных процессов наблюдается в нарушении проприоцепции, тактильных ощущений и ощущений боли. Им же отмечается, что ощущения не дифференцированы, снижена адаптация органов чувств, пороги чувствительности отклоняются от нормы [8].

Старшие школьники с интеллектуальной недостаточностью обладают следующими характеристиками восприятия: недостаточной осмысленностью и обобщенностью. Учащимся доставляет много затруднений выделение главного, существенного в объекте [9]. В этом можно убедиться, диагностируя способность к восприятию посредством заданий с использованием сюжетных картин. Обратимся к исследованиям И. М. Соловьева, К. И. Вересотской, 3. А. Евлаховой, А. П. Гозовой, которые освещали данную особенность сенсорно-перцептивного развития школьников. По их данным, такие дети не способны установить действительные отношения между объектами, действующими лицами, не понимают необходимых связей. Наибольшие затруднения для них вызывает понимание изображенных на картине средств, которые отражают внутренние состояния человека [4].

У детей с нарушенным интеллектом восприятие отличается относительной константностью (относительным постоянством воспринимаемых характеристик предметов (величины, цвета, формы) при изменении условий их рассматривания), как и у детей с интеллектуальной нормой. Но, в отличие от последних, у детей с нарушением интеллекта это свойство восприятия выражено в меньшей степени [6]. 
Чтобы отразить особенности такой части сенсорно-перцептивных процессов, как цветовая чувствительность, рассмотрим исследования Т. Н. Головиной [10] и И. А. Грошенкова [11], в которых указано, что у детей с интеллектуальной недостаточностью часто встречается снижение чувствительности к цвету. К тому же на протяжении 5-6 лет развитие данного вида чувствительности протекает чрезвычайно медленно. Большая часть из данного контингента детей могут научиться правильному узнаванию и называнию только основных цветов, а те же действия относительно промежуточных и слабонасыщенных цветовых оттенков вызывают у них зачастую непреодолимые сложности.

Опираясь на опыты М. М. Нудельмана, можно сделать вывод о слабой дифференциации процесса восприятия данной категории детей. И. М. Соловьев утверждал, что одной из специфических черт школьников с нарушениями интеллекта является узость восприятия [5]. Такая особенность подразумевает уменьшение способностей к обозрению окружающего пространства и обнаруживается во время наблюдений за окружающей обстановкой у детей данной категории. Участок с большим количеством предметов воспринимается ими с опусканием, в первую очередь, слабо выделяющихся, мелких объектов [12].

Данная специфика сенсорно-перцептивного развития, описанная нами выше, отражается и на узнавании предметов, создании и использовании образов предметов. И при нормальном, и при искаженном пути развития интеллектуальных способностей тенденция узнавания предметов будет той же. На смену ошибочному узнаванию приходит правильное, но более обобщенное узнавание. В процессе обучения это узнавание будет переходить в специфическое, включая в себя указание отдельных признаков, особенностей. Безусловно, характеризуемая нами категория учащихся отличается более долгим сохранением ошибочного узнавания, частым допуском ошибок, которые имеют более грубый характер, чем у нормально развивающихся сверстников [13].

Последняя специфическая особенность сенсорно-перцептивной стороны познавательной сферы, которую нам бы хотелось раскрыть в теоретической части этой работы - это восприятие времени у детей с недостаточностью интеллектуальной деятельности. И. И. Финкельштейн изучал особенности восприятия учащихся с интеллектуальной недостаточностью с 1 по 7 класс специальной школы. Он исследовал представления и понятия о времени, не связанные и связанные со счетом, представления и понятия о времени как об историческом отрезке. Сравнительный анализ результатов учащихся первого класса специальной школы и обычной показал, что способность к ориентировке во времени у нормально развивающихся детей намного выше, чем у детей с нарушенным интеллектом. Понятие временной длительности формируется у таких детей только в старших классах, т. е. значительно позже представлений о последовательности [14]. 
КОРРЕКЦИОННАЯ ПСИХОЛОГИЯ

\section{МЕТОДЫ}

В ходе нашего исследования, проведенного в период с сентября 2019 по май 2020 г. на базе ГКОУ РО «Ростовская школа-интернат № 41», были частично подтверждены теоретические аспекты, обозначенные выше, а также была установлена специфика сенсорно-перцептивной стороны старших школьников при работе в онлайн-формате. Для организации проведения эксперимента нами были использованы рекомендации, освещенные в работах Э. А. Каверовой, О. Г. Болдиновой, А. М. Егорчева, Д. М. Маллаева, О. А. Бажуковой $[15,16,17,18]$.

Используя метод наблюдения, мы фиксировали особенности восприятия детей старшего школьного возраста в процессе проведения диагностики и на протяжении всей коррекционной деятельности. Так как исследование данных функций было смежным с основным экспериментом, включающим в себя изучение особенностей письменной речи у школьников с нарушениями интеллектуальной деятельности, то помимо метода наблюдения нами были использованы только метод анализа теоретической и практической литературы по проблеме исследования и описательный метод. Выборка для наблюдения составляла 30 человек, 10 из шестого класса, 20 - ученики седьмого класса. На первых же этапах была отмечена инертность психических процессов у каждого участника наблюдаемой группы [19]. Безусловно, степень сформированности сенсорно-перцептивной стороны речи, как было нами отмечено, находится в непосредственной зависимости от степени нарушения интеллекта.

\section{РЕЗУЛЬТАТЫ}

В рамках проводимого нами эксперимента, направленного на изучение особенностей письменной речи у учащихся старших классов с интеллектуальной недостаточностью [4], нами было установлено, что темп зрительного восприятия у таких детей значительно снижен. Это проявлялось и на диагностическом этапе, и во время коррекционной работы, включающей в себя элементы мнемотехник, в частности, метод «Mind maps», разработанный и представленный американским ученым Т. Бьюзеном [20]. Несмотря на сниженный темп зрительного восприятия, результаты заданий, основанных на данном методе, были более успешными, потому что дети могли отражать свой взгляд на изучаемые предметы в привычных их восприятию образах. Кроме того, нельзя не отметить ускорение темпа восприятия схематических изображений, которые более просты по строению, чем, к примеру, сюжетные картины.

Характеризуя специфику восприятия пространства и времени, отметим, что нарушения пространственных восприятий группами зарубежных и отечественных ученых, таких как Г. Сантуччи, М. Пеше, Г. Перга, С. Л. Мирской, 
Н. П. Павлова и др., рассматриваются как один из наиболее характерных дефектов, сопутствующий нарушениям интеллекта. Описывая эти компоненты сенсорно-перцептивных процессов, отразим следующие особенности: у старших школьников с тяжелой степенью нарушения интеллектуальной деятельности ярко выражены трудности восприятия в данной сфере, пространственно-временные отношения или формируются особо замедленно, или не формируются вовсе. Однако у других детей, находящихся с ними в одном классе, которые находятся в меньшей возрастной группе, но обладают более легкой степенью ментального нарушения, преобладает относительная развитость как временных, так и пространственных отношений.

Наша исследовательская работа в марте 2020 г. была переведена в дистанционный режим, вследствие пандемии. Данная ситуация дала возможность перевести наблюдение в иное, непривычное для всех предыдущих исследований русло. На наш взгляд, данная форма работы негативно сказалась на способности к восприятию и усваиванию материала. Возможность получения полноценных ощущений резко уменьшилась, соответственно претерпели изменения и процессы восприятия. Коррекционно-развивающая работа стала менее эффективной, что было видно из результатов промежуточного оценивания освоенного материала.

\section{ОБСУЖДЕНИЕ РЕЗУЛЬТАТОВ}

Проведенное нами наблюдение позволило увидеть сферу перцептивного развития учащихся с нарушениями интеллекта под иным углом. В первую очередь, благодаря использованию метода «Mind maps» в рамках основного исследования, стало возможным определение особенностей восприятия школьников при создании ими схематических изображений. Также особую значимость имеет возможность оценивания уровня ощущений и восприятия детей исследуемой нами группы при переходе на дистанционный формат обучения.

В заключение необходимо подчеркнуть, что дети старшего школьного возраста с интеллектуальной недостаточностью имеют потенциал для развития сенсорно-перцептивных процессов, который может быть реализован в видах деятельности разного рода. Зная специфику формирования этой стороны познавательной сферы и учитывая ее при проведении коррекционно-развивающей работы, можно значительно повысить уровень их перцептивного развития.

\section{ЛИТЕРАТУРА}

1. Выготский Л. С. Психология развития человека. М.: Смысл, Эксмо, 2005. 1136 c. 
КОРРЕКЦИОННАЯ ПСИХОЛОГИЯ

2. Рубинштейн С. Л. Основы общей психологии. М. [и др.]: Питер, 2012. 705 с.

3. Маклаков А. Г. Общая психология: учебное пособие для студентов вузов и слушателей курсов психологических дисциплин. М. [и др.]: Питер, 2012. 582 c.

4. Рубинштейн С. Я. Психология умственно отсталого школьника. 3-е изд., перераб. и доп. М.: Просвещение, 1986. 192 с.

5. Виноградова А. Д., Липецкая Е. И., Матасов Ю. Т., Ушакова И. П. Практикум по психологии умственно отсталого ребенка. М.: Просвещение, 1985. $144 \mathrm{c}$.

6. Маллаев Д. М., Омарова П. О., Бажукова О. А. Психология общения и поведения умственно отсталого школьника. СПб.: Речь, 2009. 159 с.

7. Психология лиц с умственной отсталостью: учебно-методическое пособие / Сост. Е. А. Калмыкова. Курск: Курский гос. ун-т, 2007.

8. Обучение детей с нарушениями интеллектуального развития: (Олигофренопедагогика): учеб. пособие для студ. высш. пед. учеб. заведений / Под ред. Б. П. Пузанова. М.: Академия, 2008. 272 с.

9. Процко Т. А. Психология школьника с интеллектуальной недостаточностью (умственной отсталостью):Учебно-методическое пособие. Мн., 2006.

10. Головина Т. Н. Изобразительная деятельность учащихся вспомогательной школы. М.: Педагогика, 1974. 117 с.

11. Грошенков И. А. Изобразительная деятельность в специальной (коррекционной) школе VIII вида: Учеб. пособие для студ. высш. пед. учеб. заведений. М.: Академия, 2002. 208 с.

12. Войлокова Е. Ф., Андрухович Ю. В., Ковалева Л. Ю. Сенсорное воспитание дошкольников с интеллектуальной недостаточностью. Учебно-методическое пособие. СПб.: КАРО, 2005. 294 с.

13. Переслени Л. И. Механизмы нарушения восприятия у аномальных детей (психофизиологическое исследование). М.: Педагогика, 1984. 161 с.

14. Финкельштейн И. Н. Представления и понятие о времени у детей-олигофренов. М.: Просвещение, 1998. 294 с.

15. Болдинова О. Г., Каверова Э. А. Моделирование инклюзивной образовательной среды в современной школе // Педагогический вестник. 2020. № 14. С. 16-18.

16. Bazhukova O. A., Mallaev D. M., Boldinova O. G. Criteria for teachers' professional competence in design of inclusive education // ARPHA Proceedings. 2020. № 3. P. 199-206. DOI: 10.3897/ap.2.e0199

17. Mallaev D. M., Bazhukova O. A., Magomedova S. A., Damadaeva A. S. Spiritual and moral education of schoolchildren as the basis of their mental and psychological well-being // Journal of Pharmaceutical Sciences and Research. 2018. Vol. 10, № 7. P. 1856-1859. 
18. Mardakhaev L. V., Egorychev A. M., Mallaev D. M., Varlamova E. Yu., Kostina E. A. Organizing educational process in higher school on basis of requirements to teacher in polycultural environment // Science for Education Today. 2019. Vol. 9, № 2. P. 23-35. DOI: 10.15293/2658-6762.1902.02

19. Вихарева М. Б. Минимизация дисграфических ошибок у школьников с интеллектуальной недостаточностью // Материалы Международного молодежного научного форума «ЛОМОНОСОВ-2020» / Отв. ред. И. А. Алешковский, А. В. Андриянов, Е. А. Антипов. М.: МАКС Пресс, 2020.

20. Ahlberg M. Varieties of concept mapping // Concept Maps: Theory, Methodology, Technology: Proc. of the First Int. Conference on Concept Mapping / A. J. Cañas, J. D. Novak, F. M. González (Eds.). Pamplona, 2004.

\section{REFERENCES}

1. Vygotskii L. S. Psychology of human development. Moscow, Smysl, Eksmo, 2005. 1136 p. (in Russ.).

2. Rubinstein S. L. Fundamentals of general psychology. Moscow [and others], Piter, 2012. 705 p. (in Russ.).

3. Maklakov A. G. General psychology: Manual for university students and students of psychology courses. Moscow [and others], Piter, 2012. 582 p. (in Russ.).

4. Rubinstein S. Ya. Psychology of mentally retarded schoolchildren. 3rd ed. and add. Moscow, Prosveshchenie, 1986. 192 p. (in Russ.).

5. Vinogradova A. D., Lipetskaya E. I., Matasov Yu. T., Ushakova I. P. Practicum on the psychology of a mentally retarded child. Moscow, Prosveshchenie, 1985. 144 p. (in Russ.).

6. Mallaev D. M., Omarova P. O., Bazhukova O. A. Psychology of communication and behavior of mentally retarded schoolchildren. St. Petersburg, Rech', 2009. 159 p. (in Russ.).

7. Kalmykova E. A. (Comp.). Psychology of persons with mental retardation: Tutorial. Kursk, Kursk State University, 2007. (in Russ.).

8. Puzanov B. P. (Ed.). Teaching children with intellectual disabilities: (Oligophrenopedagogy): Manual for students of higher pedagogical educational institutions. Moscow, Academiya, 2008. 272 p. (in Russ.).

9. Protsko T. A. Psychology of a schoolchild with intellectual disability (mental retardation): Tutorial. Minsk, 2006. (in Russ.).

10. Golovina T. N. Visual activity of students of the auxiliary school. Moscow, Pedagogika, 1974. 117 p. (in Russ.).

11. Groshenkov I. A. Visual activity in a special (correctional) school of the VIII type: Manual for students of higher pedagogical educational institutions. Moscow, Academiya, 2002. 208 p. (in Russ.). 
КОРРЕКЦИОННАЯ ПСИХОЛОГИЯ

12. Voilokova E. F., Andrukhovich Yu. V., Kovaleva L. Yu. Sensory education of preschoolers with intellectual disabilities. Tutorial. St. Petersburg, KARO, 2005. 294 p. (in Russ.).

13. Peresleni L. I. Mechanisms of impaired perception in abnormal children (psychophysiological study). Moscow, Pedagogika, 1984. 161 p. (in Russ.).

14. Finkelstein I. N. Ideas and concept of time in oligophrenic children. Moscow, Prosveshchenie, 1998. 294 p. (in Russ.).

15. Boldinova O. G., Kaverova E. A. Modeling an inclusive educational environment in a modern school. Pedagogicheskii vestnik, 2020, no. 14, pp. 16-18. (in Russ.).

16. Bazhukova O. A., Mallaev D. M., Boldinova O. G. Criteria for teachers' professional competence in design of inclusive education. ARPHA Proceedings, 2020, no. 3, pp. 199-206. DOI: 10.3897/ap.2.e0199

17. Mallaev D. M., Bazhukova O. A., Magomedova S. A., Damadaeva A. S. Spiritual and moral education of schoolchildren as the basis of their mental and psychological well-being. Journal of Pharmaceutical Sciences and Research, 2018, V. 10, no. 7, pp. 1856-1859.

18. Mardakhaev L. V., Egorychev A. M., Mallaev D. M., Varlamova E. Yu., Kostina $E$. A. Organizing educational process in higher school on basis of requirements to teacher in polycultural environment. Science for Education Today, 2019, V. 9, no. 2, pp. 23-35. DOI: 10.15293/2658-6762.1902.02

19. Vikhareva M. B. Minimization of dysgraphic errors in schoolchildren with intellectual disabilities. In: I. A. Aleshkovskii, A. V. Andriyanov, E. A. Antipov (Eds.). Materials of the International Youth Scientific Forum "LOMONOSOV-2020". Moscow, MAKS Press, 2020. (in Russ.).

20. Ahlberg M. Varieties of concept mapping. In: A. J. Cañas, J. D. Novak, F. M. González (Eds.). Concept Maps: Theory, Methodology, Technology: Proc. of the First Int. Conference on Concept Mapping. Pamplona, Spain, 2004. 